\title{
Polarization reversal induced by heating-cooling cycles in MgO doped lithium niobate crystals
}

\author{
V. Ya. Shur, ${ }^{1}$ E. A. Mingaliev, ${ }^{1}$ V. A. Lebedev,${ }^{2}$ D. K. Kuznetsov, ${ }^{1}$ and D. V. Fursov ${ }^{1,3}$ \\ ${ }^{1}$ Ferroelectric Laboratory, Institute of Natural Sciences, Ural Federal University, Lenin Ave. 51, \\ 620000 Ekaterinburg, Russia \\ ${ }^{2}$ Faculty of Materials Science, Lomonosov Moscow State University, Leninskie Gory, 119991 Moscow, Russia \\ ${ }^{3}$ Consulate General of the United States, Gogol Street, 15, 620151 Ekaterinburg, Russia
}

(Received 29 October 2012; accepted 15 January 2013; published online 8 May 2013)

\begin{abstract}
Polarization reversal during heating-cooling cycles was investigated in $\mathrm{MgO}$ doped lithium niobate (MgO:LN) crystal using piezoresponse force microscopy. The essential dependence of the domain structure evolution scenario on the maximal temperature in the cycle has been revealed experimentally. It has been shown that the heating of the engineered domain matrix from room temperature to $85^{\circ} \mathrm{C}$ leads to light size reduction of the isolated domains at the matrix edges, whereas the heating to $170^{\circ} \mathrm{C}$ leads to essential reduction of the domain size. The opposite strong effect of the domain formation and growth during cooling after pulse heating have been revealed in single domain $\mathrm{MgO}: \mathrm{LN}$. The simulation of the time dependence of the pyroelectric field during heating-cooling cycle allowed to reveal the temperature hysteresis and to explain all observed effects taking into account the temperature dependence of the bulk conductivity. (C) 2013 AIP Publishing LLC [http://dx.doi.org/10.1063/1.4801969]
\end{abstract}

\section{INTRODUCTION}

The single crystals of lithium niobate $\mathrm{LiNbO}_{3}(\mathrm{LN})$ and lithium tantalate $\mathrm{LiTaO}_{3}$ (LT) family have become the most important objects of the domain engineering due to unique nonlinear-optical and electro-optical properties and simple domain structure. ${ }^{1-3} \mathrm{LN}$ and LT with precise periodic domain structure (PPLN and PPLT) produced by electric field poling allow to create various nonlinear-optical and electrooptical devices. ${ }^{4-6}$ PPLN and PPLT are used for laser light frequency conversion with high efficiency based on quasiphase-matching effect. ${ }^{7-10}$

It is known that the domain structure in the crystals of LN and LT family can be changed as a result of thermal cycling under the action of pyroelectric field. ${ }^{11-14}$ Two aspects of this effect are important for application. First, the stable single domain state or tailored domain pattern is crucial for the optical devices used at the elevated temperatures. ${ }^{15,16}$ Second, the cooling after pulse heating can be used for producing of the stable micro- and nanodomain structures. ${ }^{17-26}$ The utilization of both antagonistic effects needs deep understanding of the domain structure evolution under the action of pyroelectric field which appears during heating-cooling cycles.

Recently the thermal-induced backswitching effect (decreasing of domain sizes) has been reported in nearstoichiometric LT single crystals. ${ }^{27}$ The effect was observed for small tailored domains inverted using conductive tip of the scanning probe microscope (SPM) in 3- $\mu \mathrm{m}$ thick-plate for the maximum heating temperature varied from 40 to $100^{\circ} \mathrm{C}$. It has been shown that the backswitching degree is dependent on the temperature maximum. The inverse effect representing thermal-induced domain growth was revealed in near-stoichiometric $\mathrm{LN}$ for the maximum heating temperature varied from 100 to $180^{\circ} \mathrm{C} .^{28}$ The effect has been studied for the hexagonal domains inverted by SPM tip in 800-nm-thick-plate. The mechanism of the thermal-induced polarization reversal has not been clarified in these papers.

The formation of the stable nanoscale surface domain structures after laser pulse heating was demonstrated experimentally in LN. The irradiation of single domain LN by intense ultraviolet laser with pulse duration $7 \mathrm{~ns}$ induces shallow surface domain rays with width below $300 \mathrm{~nm}$ and depth about $2 \mu \mathrm{m} .{ }^{17}$ In contrast, the irradiation by infrared laser (wavelength $10.6 \mu \mathrm{m}$ ) with pulse duration in millisecond range initiates the formation of the bulk domain structure consisting of nanoscale domain rays with depth up to $200 \mu \mathrm{m}^{20,23,26}$

In this work, we report the study of the polarization reversal as a result of heating-cooling cycles in congruent $\mathrm{MgO}$ doped $\mathrm{LN}$ (MgO:LN). The change of the sizes of isolated domains produced by local field applied using conductive SPM tip has been measured by piezoelectric force microscopy (PFM). The growth of nucleated domains induced by pulse heating was studied by in situ visualization. The calculated evolution of the pyroelectric field during heating-cooling cycle has been used for explanation of the experimental results.

\section{EXPERIMENT}

The change of the sizes of isolated domains was studied in 300- $\mu$ m-thick single domain plates of singlecrystalline congruent $\mathrm{LN}$ doped by $5 \%$ weight of $\mathrm{MgO}$ (MgO:LN) produced by Yamaju Ceramics, Japan. The plates were cut normally to the polar axis and thinned by lapping and polished carefully. The sample was glued by conductive epoxy to the grounded metal disk. The domain switching was carried out by application of the electric field 
using conductive SPM tip. The polarization reversal and domain visualization in PFM mode have been done by SPM NanoLaboratory NTEGRA Aura (NT-MDT, Russia). The cantilevers NSC15 (MikroMasch, Estonia) with conductive TiPt coating were used. The domains were produced by application of the single rectangular field pulse with duration $10 \mathrm{~s}$ and amplitude $200 \mathrm{~V}$ at room temperature (RT). A heating table of SPM allowed to change the sample temperature from RT to $200{ }^{\circ} \mathrm{C}$ with required constant heating and cooling rate up to $170^{\circ} \mathrm{C} / \mathrm{min}$.

The engineered domain structure was visualized by PFM phase and amplitude images at RT. The domain images were obtained after each heating or cooling stage. All operations were performed in air with normal pressure.

The domain visualization was realized by applying an $a c$ driving voltage with amplitude 5-10 $\mathrm{V}$ and frequency $17.4 \mathrm{kHz}$ through the conductive tip while scanning the surface. The scanning time was about $10 \mathrm{~min}$. Visualization and switching using SPM tip were described in details in Refs. 29 and 30.

The stability of the domain structure during visualization procedure was examined by comparison of the images obtained by multiple PFM scanning at given temperature. The absence of any noticeable domain structure changes induced by scanning has been confirmed experimentally. Therefore, we can claim that the obtained polarization reversal has been caused by the heat treatment only.

The nucleation and growth of domains induced by pulse heating was studied in 500- $\mu \mathrm{m}$-thick plates of $\mathrm{MgO}: \mathrm{LN}$. The pulse heating was realized by two methods: (1) current along the electrode deposited on the polar surface and (2) infrared laser irradiation.

For current heating, $\mathrm{In}_{2} \mathrm{O}_{3}: \mathrm{SnO}_{2} 400$-nm-thick electrode with $1 \times 4 \mathrm{~mm}^{2}$ area was deposited on $\mathrm{Z}+$ surface. The current pulses with duration $0.5 \mathrm{~ms}$ and amplitude range from 2 to $3.5 \mathrm{~A}$ have been used. Thus, the energy density was varied from 5 to $15 \mathrm{~J} / \mathrm{cm}^{2}$.

For laser heating, the pulsed $\mathrm{CO}_{2}$ laser with wavelength $10.6 \mu \mathrm{m}$ was used for sample irradiation by single pulse with duration ranged from 1.0 to $4.5 \mathrm{~ms}$. The focusing of the laser irradiation by $\mathrm{ZnSe}$ lens allows to change the energy density from 5 to $30 \mathrm{~J} / \mathrm{cm}^{2}$. The estimated maximal temperature of the sample surface $900^{\circ} \mathrm{C}$ has been below the melting point for $\mathrm{LN}$.

\section{RESULTS}

The polarization reversal after heating and cooling stages was measured by analysis of the PFM domain images. The domain structure evolution has been characterized in terms of the averaged relative change of the domain area.

The engineered $5 \times 5$ matrix with $5-\mu \mathrm{m}$-period of the isolated domains with averaged area $1.8 \mu \mathrm{m}^{2}$ was produced at RT (Fig. 1(a)). The changes of the domain structure were measured after each heating or cooling stages: (1) first heating to $85^{\circ} \mathrm{C}$ (Fig. 1(b)), (2) subsequent cooling to RT (Fig. 1(c)), (3) second heating to $170^{\circ} \mathrm{C}$ (Fig. 1(d)). The temperature change rate for heating and cooling was about $10^{\circ} \mathrm{C} / \mathrm{min}$. It was shown by confocal Raman microscopy

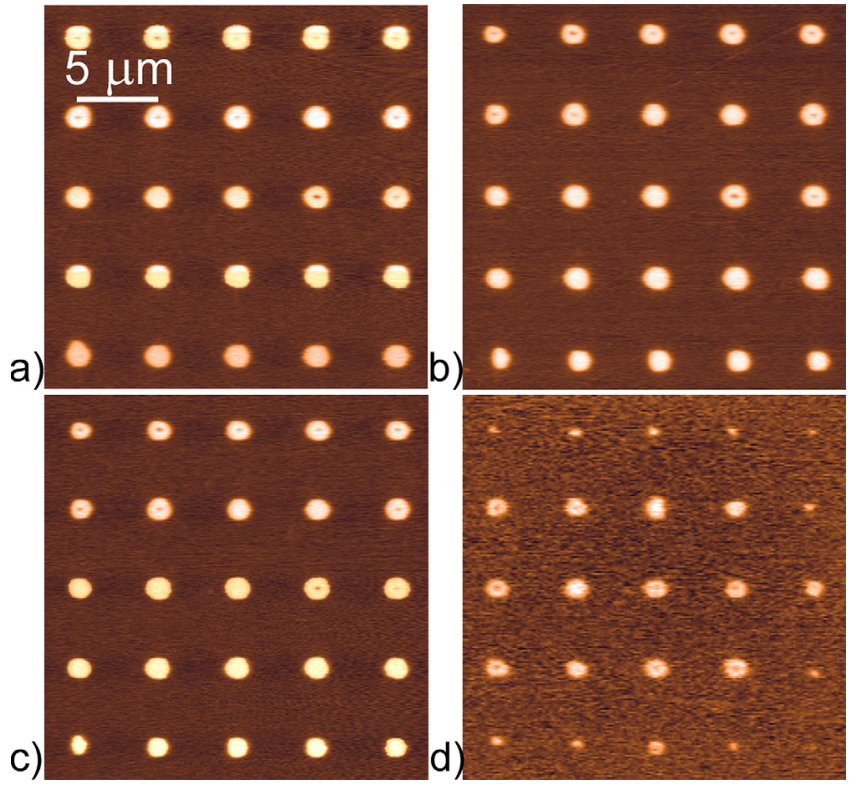

FIG. 1. PFM images of the domain matrix: (a) as engineered at RT, (b) after heating to $85^{\circ} \mathrm{C}$, (c) after cooling to RT, (d) after heating to $170^{\circ} \mathrm{C}$.

that the needle-like domains produced by field application using conductive SPM tip after heating-cooling cycle intergrew through the sample and possessed the neutral domain walls.

The statistical analysis of the domain images allowed to reveal that the first heating stage $\left(\mathrm{RT} \rightarrow 85^{\circ} \mathrm{C}\right)$ led to decreasing of the domain sizes on $17 \%$ (down to $1.48 \mu \mathrm{m}^{2}$ ) in the first and the last rows only. The domain areas persisted after the cooling stage $\left(85^{\circ} \mathrm{C} \rightarrow \mathrm{RT}\right)$. The second heating stage $\left(\mathrm{RT} \rightarrow 170^{\circ} \mathrm{C}\right)$ resulted in essential inhomogeneous domain backswitching: representing the five times reduction of the averaged domain area at the edges of the domain matrix (down to $0.26 \mu \mathrm{m}^{2}$ ) whereas the domains in the central part diminished on $35 \%$ only (down to $1.17 \mu \mathrm{m}^{2}$ ).

The inverse effect (domain growth) was obtained for fast heating by current and pulse laser irradiation with heating rate above $100000^{\circ} \mathrm{C} / \mathrm{s}$. The in situ optical observation allowed to reveal that the pulse heating both by current and laser irradiation led to domain nucleation and growth which started during cooling. The isolated domains appeared after pulse heating with energy density above $5 \mathrm{~J} / \mathrm{cm}^{2}$ (Fig. 2(a)), whereas the complicated structures of strictly oriented domain rays were formed for energy density above $12 \mathrm{~J} / \mathrm{cm}^{2}$ (Figs. 2(b) and 3(a)). The submicron width of the domain rays has been revealed by SPM visualization with high spatial resolution (Fig. 3(b)).

For explanation of the domain structure evolution we have calculated the temperature dependence of $\mathrm{E}_{\mathrm{pyr}}$ for heating-cooling cycle. We have considered the uniform temperature change in infinite ferroelectric plate without electrodes. The time and temperature dependent pyroelectric field $\mathrm{E}_{\mathrm{pyr}}(\mathrm{T}, \mathrm{t})$ was estimated as a sum of depolarization field $\mathrm{E}_{\mathrm{dep}}(\mathrm{T}(\mathrm{t}))$ produced by bound charges and screening field $\mathrm{E}_{\mathrm{scr}}(\mathrm{t}(\mathrm{T}))$ produced by bulk screening charges

$$
\mathrm{E}_{\mathrm{pyr}}(\mathrm{T}, \mathrm{t})=\mathrm{E}_{\text {dep }}(\mathrm{T}(\mathrm{t}))-\mathrm{E}_{\mathrm{scr}}(\mathrm{t}(\mathrm{T})) .
$$




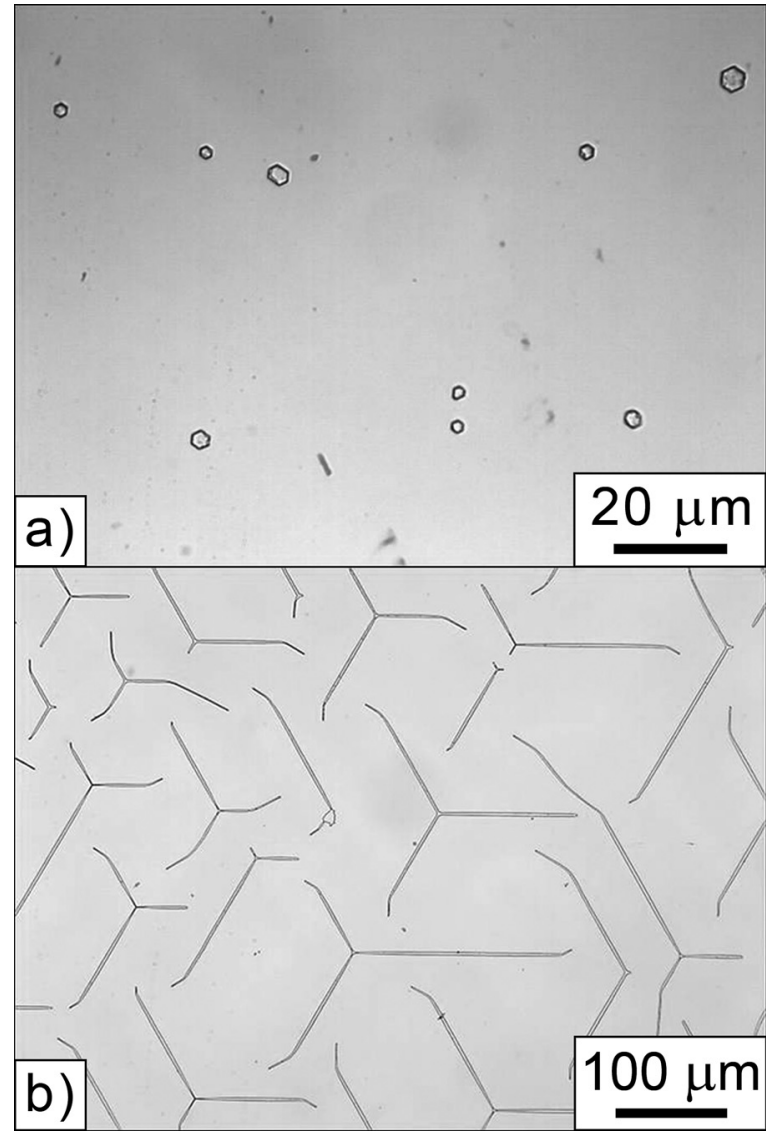

FIG. 2. Domain structures induced in $\mathrm{MgO}: \mathrm{LN}$ after pulse current heating of polar surface. Energy density: (a) above $5 \mathrm{~J} / \mathrm{cm}^{2}$, (b) above $12 \mathrm{~J} / \mathrm{cm}^{2}$. Optical images of domain structure revealed by chemical etching.

The temperature dependence of the bulk conductivity with electronic and ionic inputs was taken into account

$$
\sigma(\mathrm{T})=\sigma_{\mathrm{el}} \exp \left(-\mathrm{W}_{\mathrm{ac}}{ }^{\text {el }} / \mathrm{kT}\right)+\sigma_{\mathrm{ion}} \exp \left(-\mathrm{W}_{\mathrm{ac}} \text { ion } / \mathrm{kT}\right),
$$

where $\mathrm{W}_{\mathrm{ac}}{ }^{\mathrm{el}}$ is the activation energy for the electronic conductivity and $\mathrm{W}_{\mathrm{ac}}{ }^{\text {ion }}$ is the activation energy for the ionic conductivity.

The time constant characterized the screening of the depolarization field without external screening is defined by

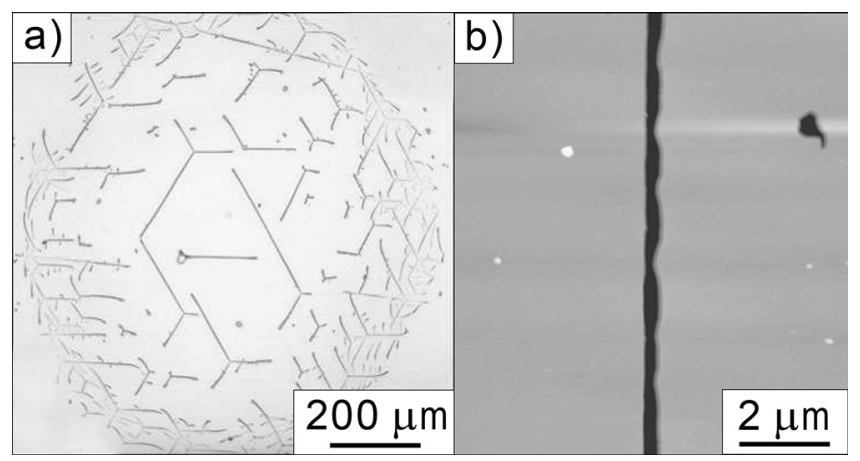

FIG. 3. Domain structure induced in $\mathrm{MgO}: \mathrm{LN}$ after pulse infrared laser heating of polar surface. Energy density is above $12 \mathrm{~J} / \mathrm{cm}^{2}$. (a) Optical image of the domain structure; (b) SPM image of the domain ray. The domain structure revealed by chemical etching.

$$
\tau(\mathrm{T})=\varepsilon(\mathrm{T}) \varepsilon_{0} / \sigma(\mathrm{T}),
$$

where $\varepsilon(T)$ is the temperature dependent dielectric permittivity and $\varepsilon_{0}$ is dielectric constant.

The following equation can be written for relaxation of the screening charge density $\rho_{\text {scr }}(\mathrm{T}(\mathrm{t}))$ :

$$
\mathrm{d} \rho_{\text {scr }}(\mathrm{T}(\mathrm{t})) / \mathrm{dt}=-\left[\rho_{\text {scr }}(\mathrm{T}(\mathrm{t}))-\mathrm{P}_{\mathrm{S}}(\mathrm{T}(\mathrm{t}))\right] / \tau(\mathrm{T}(\mathrm{t})),
$$

where $\mathrm{P}_{\mathrm{S}}(\mathrm{T}(\mathrm{t}))$ is the temperature dependent spontaneous polarization.

Solution of the present equation is

$$
\begin{aligned}
\rho_{\text {scr }}(\mathrm{T}(\mathrm{t}))= & -\mathrm{P}_{\mathrm{S}}\left(\mathrm{T}_{0}\right) \cdot \exp \left[-\int_{0}^{\mathrm{t}} \frac{1}{\tau\left(\mathrm{T}\left(\mathrm{t}^{\prime}\right)\right)} \mathrm{dt}^{\prime}\right] \\
& -\int_{0}^{\mathrm{t}} \frac{\mathrm{P}_{\mathrm{S}}\left(\mathrm{T}\left(\mathrm{t}^{\prime \prime}\right)\right)}{\tau\left(\mathrm{T}\left(\mathrm{t}^{\prime \prime}\right)\right)} \cdot \exp \left[\int_{0}^{\mathrm{t}^{\prime \prime}} \frac{1}{\tau\left(\mathrm{T}\left(\mathrm{t}^{\prime}\right)\right)} \mathrm{dt}^{\prime}\right. \\
& \left.-\int_{0}^{\mathrm{t}} \frac{1}{\tau\left(\mathrm{T}\left(\mathrm{t}^{\prime}\right)\right)} \mathrm{dt}^{\prime}\right] \mathrm{dt^{ \prime \prime }},
\end{aligned}
$$

where $T_{0}$ is the initial temperature of the plate.

Final equation for $\mathrm{E}_{\mathrm{pyr}}$ is the following:

$$
\mathrm{E}_{\mathrm{pyr}}(\mathrm{T}(\mathrm{t}))=\left[\mathrm{P}_{\mathrm{S}}(\mathrm{T}(\mathrm{t}))-\rho_{\text {scr }}(\mathrm{T}(\mathrm{t}))\right] / \varepsilon(\mathrm{T}) \varepsilon_{0}
$$

Temperature dependence of $\mathrm{E}_{\mathrm{pyr}}$ has been calculated by Eq. (6) for heating and cooling of LN plate with constant rate: $\mathrm{dT} / \mathrm{dt}=10^{\circ} \mathrm{C} / \mathrm{min}$ (Fig. 4). The linear increase of $\mathrm{E}_{\mathrm{pyr}}$ is obtained in the temperature range where the bulk

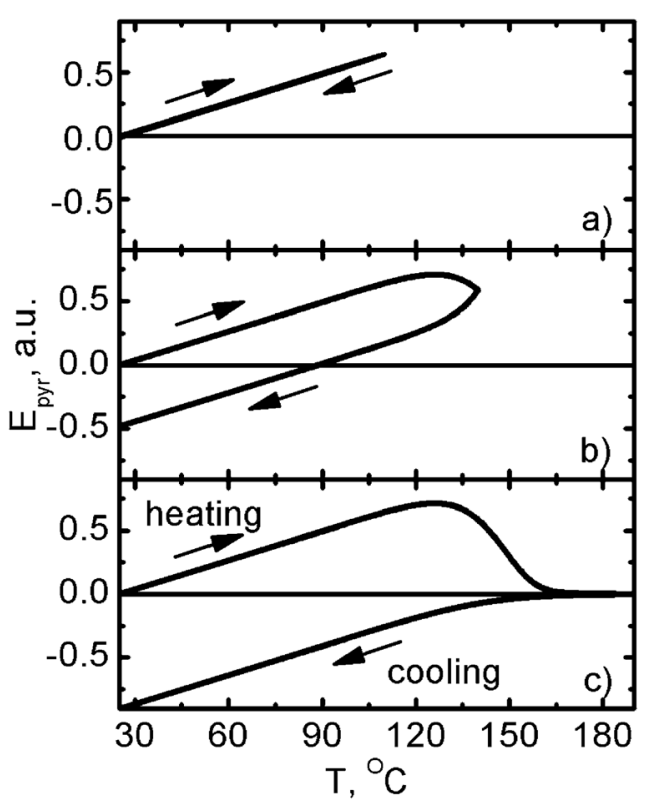

FIG. 4. Calculated temperature hysteresis of pyroelectric field for uniform heating and cooling with constant rate $10^{\circ} \mathrm{C} / \mathrm{min}$. $\mathrm{T}_{\max }$ : (a) $110^{\circ} \mathrm{C}$, (b) $140^{\circ} \mathrm{C}$, (c) $200^{\circ} \mathrm{C}$. 

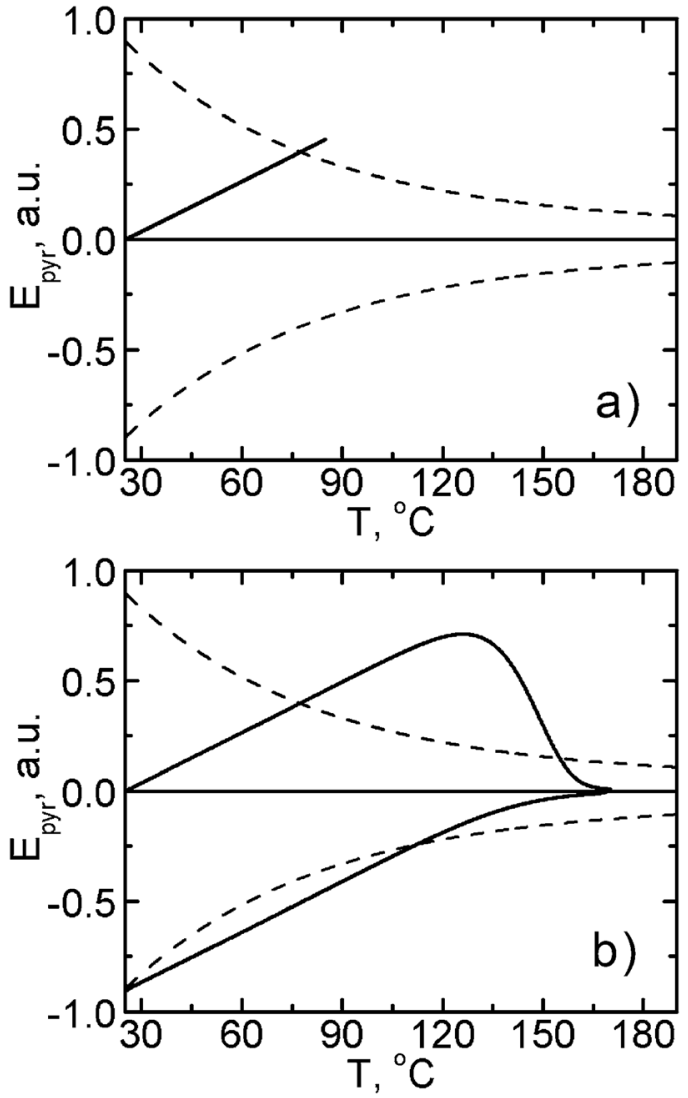

FIG. 5. Calculated temperature hysteresis of pyroelectric field for uniform heating and cooling with rate $10^{\circ} \mathrm{C} / \mathrm{min}$ (straight line) and experimental temperature dependence of nucleation threshold field (dashed line). $\mathrm{T}_{\max }$ : (a) $85^{\circ} \mathrm{C}$, (b) $170^{\circ} \mathrm{C}$.

screening by electronic conductivity is ineffective (during heating from RT up to $120^{\circ} \mathrm{C}$ ) (Fig. 4(a)). The increasing of the ionic conductivity during further heating leads to decrease of $E_{p y r}$ due to effective bulk screening (Fig. 4(b)). For high enough temperatures $\mathrm{E}_{\mathrm{pyr}}$ is negligibly small due to complete screening (Fig. 4(c)). It must be noticed that the maximal value of $\mathrm{E}_{\mathrm{pyr}}$ increased essentially with increasing of the heating rate.

The sign and the value of $\mathrm{E}_{\mathrm{pyr}}$ during heating-cooling cycle depend on the maximal temperature $\mathrm{T}_{\max }$ (Fig. 4). This fact resulted in various types of the domain structure evolution. It is necessary to take in mind that the polarization reversal occurs only for $E_{\mathrm{pyr}}(\mathrm{T})$ above the temperature dependent threshold field $\mathrm{E}_{\mathrm{th}}(\mathrm{T})$, representing the minimal field value required for appearance of new domains. ${ }^{2}$

For slow heating-cooling (the first experiment) during the first heating stage $\left(\mathrm{RT} \rightarrow 85^{\circ} \mathrm{C}\right)$ it is seen that $\mathrm{E}_{\mathrm{pyr}}$ increased and exceeded $\mathrm{E}_{\text {th }}$ within small temperature range only near the maximal heating temperature (Fig. 5(a)). This fact allows to explain the observed small decrease of the isolated domain sizes (Fig. 1(b)). The domain wall shift leads to decreasing of $\mathrm{E}_{\mathrm{pyr}}$ and terminated the further domain reduction.

During the cooling stage $\left(85^{\circ} \mathrm{C} \rightarrow \mathrm{RT}\right)$ the calculated $\mathrm{E}_{\mathrm{pyr}}$ value decreased and almost disappeared at RT (Fig. 5(a)). Thus during the whole cooling stage $\mathrm{E}_{\mathrm{pyr}}(\mathrm{T})<\mathrm{E}_{\mathrm{th}}(\mathrm{T})$ which allows to explain the obtained consistency of the domain size as a result of cooling (Fig. 1(c)).

The second heating stage $\left(\mathrm{RT} \rightarrow 170^{\circ} \mathrm{C}\right)$ resulted in essential extension of the temperature range satisfying polarization reversal condition (Fig. 5(b)). The domain size reduction effect was essentially stronger due to $E_{p y r}(T)>E_{t h}(T)$ during the long time (Fig. 1(d)).

The obtained different changes of the individual domain sizes in the center and at the edges of the domain matrix can be attributed to inhomogeneous spatial distribution of the pyroelectric field. The spatial distribution of the field produced by $5 \times 5$ matrix of the charged squares has been calculated to explain the observed effect (Fig. 6 ). It has been shown that the electric field has the maximal value at the corners and edges of the matrix. This fact allowed to explain the stronger size reduction of domains situated at the edges of the matrix (Fig. 1(d)). The exception to this rule obtained experimentally for three domains at the first column (Fig. 1(d)) is caused by existence of neighboring domains on the left side of engineered domain matrix.

For fast pulse heating (the second experiment) of the single domain sample the switching field appeared only at the cooling stage. The maximal value of pyroelectric field increased due to fast cooling after pulse heating. The formation of the self-assembled micro- and nanodomain structures after pulse laser irradiation has been studied experimentally in Refs. 18 and 20-26.

The obtained formation of the stable domain structures under the action of the pyroelectric field can be used for domain engineering in the crystals of LN family. This method will be especially useful for production of the PPLN with submicron periods.
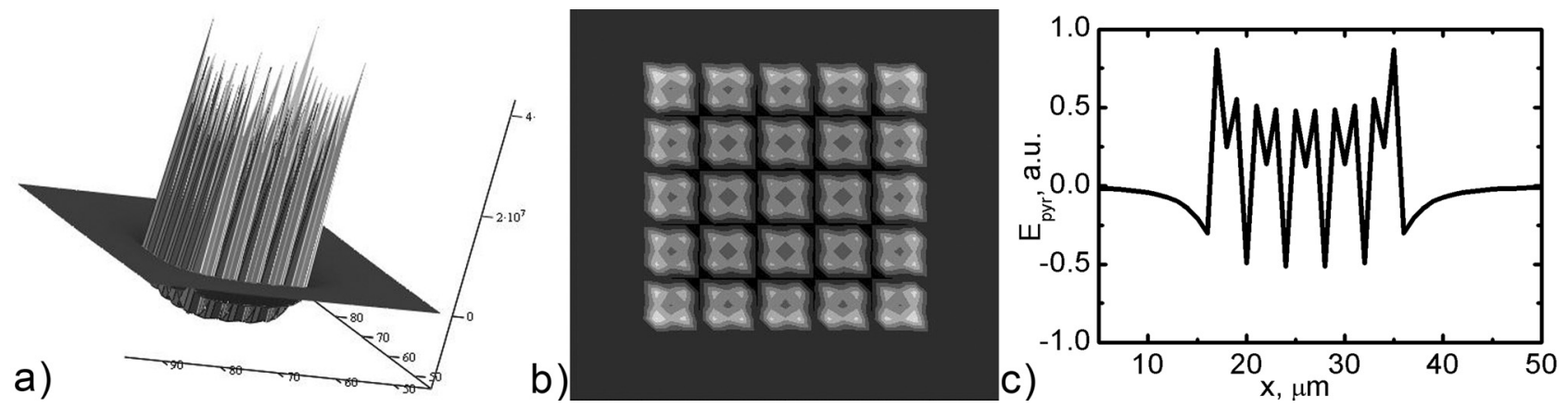

FIG. 6. Electric field distribution generated by $5 \times 5$ matrix of charged squares. (a) 3D, (b) 2D, (c) $1 \mathrm{D}$ (at the matrix center) images. 


\section{CONCLUSION}

We have investigated the polarization reversal induced by heating-cooling cycles in $\mathrm{MgO}$ doped lithium niobate crystal using piezoresponse force microscopy for domain visualization after each heating or cooling stages. It has been shown for slow heating and cooling that increasing of the maximum heating temperature leads to more effective decreasing of the sizes of domains engineered at room temperature. The fast pulse heating to high temperatures leads to opposite effect representing the domain nucleation and growth during cooling. The time dependence of pyroelectric field has been calculated taking into account the temperature dependence of electronic and ionic components of the bulk conductivity. The revealed temperature hysteresis and dependence of the pyroelectric field on the maximum heating temperature during heating-cooling cycle allowed us to explain both obtained effects. It is clear that the proposed model can be used for interpretation of the experimental results obtained in Refs. 27 and 28.

\section{ACKNOWLEDGMENTS}

The equipment of the UCSU "Modern Nanotechnology," Institute of Natural Sciences, UrFU has been used. The authors acknowledge Anton Ievlev for the PFM measurements. The research was made possible in part by RFBR and the Government of Sverdlovsk region (Grant 13-02-96041-rUral-a), by RFBR (Grants 11-02-91066-CNRS-a, 13-0201391-a), by Ministry of Education and Science (Contract 14.513.12.0006 and 16.552 117020), by OPTEC LLC and by the financial support of young scientists of the Ural Federal University development program.

${ }^{1}$ R. S. Weis and T. K. Gaylord, Appl. Phys. A 37, 191 (1985).

${ }^{2} \mathrm{~V}$. Ya. Shur, "Correlated nucleation and self-organized kinetics of ferroelectric domains," Nucleation Theory and Applications, edited by J. W. P. Schmelzer (Wiley-VCH, Weinheim, 2005), Vol. 178.

${ }^{3}$ V. Shur, E. Rumyantsev, R. Batchko, G. Miller, M. Fejer, and R. Byer, Ferroelectrics 221, 157 (1999).

${ }^{4}$ J. A. Abernethy, C. B. E. Gawith, R. W. Eason, and P. G. R. Smith, Appl. Phys. Lett. 81, 2514 (2002).
${ }^{5}$ L. Arizmendi, Phys. Status Solidi 201, 253 (2004).

${ }^{6}$ W. Sohler, H. Hu, R. Ricken, V. Quiring, C. Vannahme, H. Herrmann, D. Buchter, S. Reza, W. Grundkotter, S. Orlov, H. Suche, R. Nouroozi, and Y. Min, Opt. Photonics News 19, 24 (2008).

${ }^{7}$ J. A. Armstrong, N. Bloembergen, J. Ducuing, and P. S. Pershan, Phys. Rev. 127, 1918 (1962).

${ }^{8}$ M. Yamada, N. Nada, M. Saitoh, and K. Watanabe, Appl. Phys. Lett. 62, 435 (1993).

${ }^{9}$ R. L. Byer, J. Nonlinear Opt. Phys. 6, 549 (1997).

${ }^{10}$ D. Hum and M. Fejer, C. R. Phys. 8, 180 (2007).

${ }^{11}$ N. Ohnishi, Jpn. J. Appl. Phys. 16, 1069 (1977).

${ }^{12}$ K. Nakamura, H. Ando, and H. Zhimizu, Appl. Phys. Lett. 50, 1413 (1987).

${ }^{13}$ K. Nakamura and H. Shimizu, Appl. Phys. Lett. 56, 1535 (1990).

${ }^{14}$ V. D. Kugel and G. Rosenman, Appl. Phys. Lett. 62, 2902 (1993).

${ }^{15}$ U. Schlarb and K. Betzler, Phys. Rev. B 48, 15613 (1993).

${ }^{16}$ K. Mizuuchi, A. Morikawa, T. Sugita, and K. Yamamoto, J. Appl. Phys. 96, 6585 (2004)

${ }^{17}$ C. E. Valdivia, C. L. Sones, J. G. Scott, S. Mailis, R. W. Eason, D. A. Scrymgeour, V. Gopalan, T. Jungk, E. Soergel, and I. Clark, Appl. Phys. Lett. 86, 022906 (2005).

${ }^{18}$ V. Ya. Shur, D. K. Kuznetsov, A. I. Lobov, E. V. Nikolaeva, M. A. Dolbilov, A. N. Orlov, and V. V. Osipov, Ferroelectrics 341, 85 (2006).

${ }^{19}$ V. Ya. Shur, E. L. Rumyantsev, A. G. Shur, A. I. Lobov, D. K. Kuznetsov, E. I. Shishkin, E. V. Nikolaeva, M. A. Dolbilov, P. S. Zelenovsky, K. Gallo, and M. DeMicheli, Ferroelectrics 354, 145 (2007).

${ }^{20}$ D. K. Kuznetsov, V. Ya. Shur, S. A. Negashev, A. I. Lobov, D. V. Pelegov, E. I. Shishkin, P. S. Zelenovskiy, M. G. Ivanov, and V. V. Osipov, Ferroelectrics 373, 133 (2008).

${ }^{21}$ V. Ya. Shur, D. K. Kuznetsov, A. I. Lobov, E. I. Shishkin, P. S. Zelenovskii, V. V. Osipov, M. G. Ivanov, A. N. Orlov, and V. V. Platonov, Bull. Russ. Acad. Sci. Phys. 72, 181 (2008).

${ }^{22}$ V. Ya. Shur, D. K. Kuznetsov, A. I. Lobov, D. V. Pelegov, E. V. Pelegova, V. V. Osipov, M. G. Ivanov, and A. N. Orlov, Phys. Solid State 50, 717 (2008).

${ }^{23}$ A. I. Lobov, V. Ya. Shur, D. K. Kuznetsov, S. A. Negashev, D. V. Pelegov, E. I. Shishkin, and P. S. Zelenovskiy, Ferroelectrics 373, 99 (2008).

${ }^{24}$ D. K. Kuznetsov, V. Ya. Shur, E. A. Mingaliev, S. A. Negashev, A. I. Lobov, E. L. Rumyantsev, and P. A. Novikov, Ferroelectrics 398, 49 (2010).

${ }^{25}$ E. A. Mingaliev, V. Ya. Shur, D. K. Kuznetsov, S. A. Negashev, and A. I. Lobov, Ferroelectrics 399, 7 (2010).

${ }^{26}$ V. Y. Shur, D. K. Kuznetsov, E. A. Mingaliev, E. M. Yakunina, A. I. Lobov, and A. V. Ievlev, Appl. Phys. Lett. 99, 082901 (2011).

${ }^{27}$ X. Liu, K. Kitamura, and K. Terabe, Appl. Phys. Lett. 89, 142906 (2006).

${ }^{28}$ X. Y. Liu, K. Kitamura, Y. M. Liu, F. S. Ohuchi, and J. Y. Li, J. Appl. Phys. 110, 052009 (2011).

${ }^{29}$ E. I. Shishkin, A. V. Ievlev, E. V. Nikolaeva, M. S. Nebogatikov, and V. Ya. Shur, Ferroelectrics 374, 26 (2008).

${ }^{30}$ V. Ya. Shur, A. V. Ievlev, E. V. Nikolaeva, E. I. Shishkin, and M. M. Neradovskiy, J. Appl. Phys. 110, 052017 (2011). 
Journal of Applied Physics is copyrighted by the American Institute of Physics (AIP). Redistribution of journal material is subject to the AIP online journal license and/or AIP copyright. For more information, see http://ojps.aip.org/japo/japcr/jsp 